\title{
The Response of Market Interest Rates to Discount Rate Changes
}

T IS WELL-ESTABLISHED that discount rate changes of the same size can have markedly different effects on market interest rates. Studies of such effects, starting with Thornton (1982), have generally divided discount rate changes into two groups: "technical" changes, those made solely to keep the discount rate in line with market rates, and other "non-technical" changes." The former generally do not have a significant impact on market rates, while the latter generally do. The use of this technical/ non-technical dichotomy is predicated on the assumption that the market responds to a discount rate change based on the reasons for the change. Hakkio and Pearce (1992) find that the reasons generally fall into three categories: "(1) conditions in the market for bank reserves ...; (2) movements in intermediate targets such as the money supply and the foreign exchange value of the dollar; and (3) movements in ultimate targets such as inflation and economic growth." They observe that "changes in the rate because of type (1) factors are likely to be used to complement open market operations, while changes because of type (2) or (3) factors are more likely

The technical/non-technical dichotomy has subsequently appeared in analyses of the effects of discount rate changes on interest rates [Roley and Troll (1984), Smirlock and Yawitz (1985), Thornton (1986, 1991), Cook and Hahn (1988)] and exchange rates [Batten and Thornton (1984)],

2Hakkio and Pearce (1992), pp. 56-57.

3Thornton (1988) discusses under what conditions largeting botrowed reserves is equivalent to targeting the federal funds rate. The Fed's operating target was the federal funds to be used as signals of future Fed policy." Thus, technical changes result when the opportunity cost to banks of borrowing reserves-the federal funds rate less the discount rate-is too high or low to be consistent with attaining the Fed's operating target. Since October 1982 that target has been the level of borrowed reserves. ${ }^{3}$ Non-technical changes, on the other hand, encompass all of the other reasons the Fed might change the discount rate. Clearly a combination of the factors identified by Hakkio and Pearce can be behind a given discount rate change, so the reaction of market interest rates to discount rate changes might be more heterogeneous than the technical/non-technical dichotomy would suggest. Moreover, as the efficient markets hypothesis implies, the response of market interest rates to a discount rate change should vary with the amount of new information the discount change imparts regarding the Fed's policy intentions or the state of the economy in general. ${ }^{4}$

This article presents results on the differential response of market interest rates to discount

rate throughout the 1970 s until October 1979 when the Fed began to target non-borrowed reserves.

at is not surprising that the theoretical links between the discount rate and market interest rates have found empirical support in previous studies, given that from 1973 to 1989 , for example, $6.2 \%$ of the variation in the T-bill rate look place on only $1.3 \%$ of the days, the 56 days when the discount rate changed. 
rate changes using an econometric framework that explains more heterogeneous responses in market interest rates than the technical/nontechnical dichotomy allows. The mixture model employed here assumes that the market response is determined by either a "high-response" or "low-response" data-generating process. Inferences about which process governs a given period's interest rate depend on the information policymakers cite when they change the discount rate. Thus, we can consider hypotheses like "the higher the unemployment rate, the larger the response of market interest rates to a discount rate change of a given size." With the technical/non-technical dichotomy, in contrast, a discount rate change is described as nontechnical if the Fed mentions any number of things in its announcement, such as the inflation rate, unemployment rate, industrial production, money growth rate, etc. The technical/nontechnical dichotomy tells us little about the relative importance of these individual factors. A principal aim of the mixture model employed here is to study the influence these individual factors have on the market response.

This paper also includes some conjectural interpretations of the empirical results. For example, if the market rates respond strongly to discount rate changes when the unemployment rate is high, one might conclude that the market believes that the Fed will consistently change monetary policy in reaction to shifts in the unemployment rate. Objectively, however, the mixture model's fit and forecasts of the interest rate response serve as measures of its performance relative to the standard technical/nontechnical dichotomy. The second half of the paper addresses the implication of the efficient markets hypothesis that a discount rate change must be "news" for market rates to respond by testing whether the timing of discount rate changes is sufficiently predictable to require that models of the market's response to discount rate changes distinguish explicitly between anticipated and unanticipated changes.

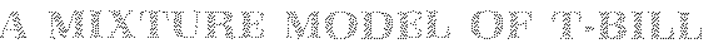

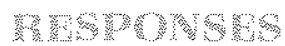

Given the limited number of discount rate changes (only 56 from 1973 to 1989), the model estimates two levels of response of 90-day Treasury bills to discount rate changes. The yield on T-bills is chosen because of the important role it plays in calculating present values for stock dividends, bond coupons, annuities, housing rents, etc. ${ }^{5}$ While the statistical model assumes that one of two mutually exclusive processes generates the change in the $T$-bill rate from any given discount rate change, the two response levels, "high" and "low," should be understood as upper and lower bounds where all fitted responses are a probability-weighted combination of the two boundary values. ${ }^{6}$ For example, if $\triangle T B$ is the change in the T-bill rate, $\triangle D R$ is the change in the discount rate and $\varepsilon$ is a meanzero stochastic disturbance, then the mixture model estimates two data-generating processes,

Process 1: $\Delta \mathrm{TB}_{\mathrm{t}}=\beta_{0}+\beta_{1} \Delta \mathrm{DR}_{\mathrm{t}}+\varepsilon_{\mathrm{t}}$

Process 2: $\Delta \mathrm{TB}_{\mathrm{t}}=\beta_{0}+\beta_{2} \Delta \mathrm{DR}_{\mathrm{t}}+\varepsilon_{\mathrm{t}}$

where $\beta_{2}$ is greater than $\beta_{1}$, so that Process 2 governs the highest responses. A single equation can describe the mixture model if we define a dummy variable, $S_{t}$, which equals one if Process 1 holds and zero if Process 2 holds.

$$
\text { (1) } \Delta \mathrm{TB}_{1}=\beta_{0}+\beta_{1} \mathrm{~S}_{\mathrm{t}} \Delta \mathrm{DDR} \mathrm{R}_{\mathrm{t}}+\beta_{2}\left(1-\mathrm{S}_{\mathrm{t}}\right) \Delta \mathrm{DR}_{\mathrm{t}}+\varepsilon_{\mathrm{t}}
$$

Equation 1 is a mixture model because the dependent variable is assumed to be drawn from a mixture of data-generating processes, in this case two. ${ }^{7}$ Because we do not observe $S_{t^{\prime}}$ only probabilistic inferences about its value are forthcoming. Hence, the inferred value of $\mathrm{S}_{\mathrm{z}}$ can lie anywhere between zero and one, making the mixture model more general than the technical/non-technical dichotomy, which restricts $S_{t}$ to equal either zero or one.
${ }^{5}$ This is because the T-bill rate serves as, or at least proxies, the "risk-free" rate of return. Applications of the term structure theory of interest rates also treat the T-bill rate as an anchor, whose current and expected future values largely determine longer-term interest rates, which are relevant for investment decisions and the level of economic activity. Portfolico insurance, through the writing and buying of options, is another activity that must constantly refer to the T-bili rate; options must be priced such that riskless hedges, which create synthetic riskless assets, do not vio. late arbitrage bounds relative to T-bill yields.
${ }^{6}$ The assumption that there are only two response levels is not to be taken literally. It is a convenient way to estimate upper and lower bounds for the T-bill response and thus generate, through mixtures of the two levels, a continuum of response levels the model can explain, while estimating only a few parameters. Of course, some responses will lie outside these bounds: the difference is simply part of the residual and not explained by the econometric model.

7 See Quandt and Ramsey (1978). 
Table 1

Mixture Model Coefficients

\begin{tabular}{cccr}
\hline Parameter & Description & Value & t-statistic \\
\hline$\beta_{0}$ & Intercept & .0018 & 1.12 \\
$\beta_{1}$ & Process 1 Response & .1449 & 4.57 \\
$\beta_{2}$ & Process 2 Response & .7743 & 10.40 \\
$\theta_{0}$ & Constant & 7.141 & 3.11 \\
$\theta_{1}$ & Magnitude and Sign of $\Delta \mathrm{DR}$ & -4.374 & 2.77 \\
$\theta_{2}$ & Unemployment Rate & -.4633 & 1.99 \\
$\sigma_{0}$ & St. Dev. Outside 1979-82 & .096 & \\
$0_{1}$ & St. Dev. During 1979-82 & .280 & \\
$\mathrm{R}^{2}$ & When $\Delta \mathrm{DR} \neq 0$ & .726 & \\
& & & \\
\hline
\end{tabular}

Furthermore, since a primary objective is to use the mixture model to create one-step-ahead forecasts of the T-bill response to discount rate changes, we pay special attention to the prior probabilities of Process 1 relative to Process 2. In particular we examine whether the prior probabilities are constant or whether they vary according to the magnitude of the discount change, previous discount rate changes, or various indicators of economic activity like inflation, output, unemployment, etc. Such variables (denoted $Z_{t}$ ) might indicate whether financial markets believe that the Fed is actively changing policy in response to economic conditions. Because drawing inferences about the likelihood of Process 1 vs. Process 2 is analogous to drawing inferences from a logit model, the logistic function provides a useful parameterization of the prior probability of Process $1^{* 8}$

(2) Prob. $\left(S_{\mathrm{t}}=1 \mid Z_{\mathrm{t}}\right)=\frac{\exp \left(Z_{\mathrm{t}}^{\prime} \theta\right)}{1+\exp \left(Z_{\mathrm{q}}^{\prime} \theta\right)}$

where all elements of $Z_{t}$ are known at time $t-1$, except the change in the discount rate. For policymakers, then, all of $\mathrm{Z}_{\mathrm{i}}$ is known before the Fed actually changes the discount rate, while for market watchers, the Prob. $\left(S_{t}=1 \mid Z_{t}\right)$ is useful for making inferences conditional on the occurrence of a given-sized discount rate change, ${ }^{9}$
Table 1 gives results from estimating the parameters in equations 1 and $2, \beta$ and $\theta$. Further details on the mixture model and its estimation are in the Appendix.

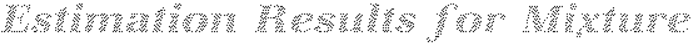

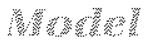

The prior probabilities for Process 1 and Process 2 are conditioned on the following variables in the results in table 1 : a constant; the change in the discount rate multiplied by the sign of the previous change; and the unemployment rate. As an explanatory variable, the change in the discount rate multiplied by the sign of the previous change responds to the following observation: Generally, large absolute changes in the discount rate lead to relatively large responses in the T-bill rate; exceptions occur, however, when the discount rate change represents a change in the direction of the discount rate (increases to decreases and vice versal. For this explanatory variable, the relationship between the absolute magnitude of the discount rate change and the T-bill response will reverse itself when the direction changes. An alternative approach would be to estimate a separate coefficient on a change-in-direction dummy variable, but, given that only eight changes in direction occur in the sample, the additional coefficient cannot be

${ }^{8}$ The parameters $\theta$ represent the derivative of the $\log$ of the odds of Process 1 versus Process 2 with respect to $Z$.

sMany professional forecasters will present different forecasts for different "scenarios." where one scenario might include an easing in monetary policy accompanied by a discount rate change of 25 basis poirts. 
estimated precisely. ${ }^{10}$ The unemployment rate is included because it might summarize the effects of real shocks on the economy. ${ }^{11}$

The hypothesis that $\beta_{1}=\beta$, is easily rejeeted, so that qualitative differences among discount rate changes of the same size do indeed cause them to differ in their effects on the T-bill rate. It is also useful to interpret the signs of the $\theta$ parameters, all three of which are significantly different from zero. The positive constant implies that, other things equal, the low. response process is more likely to hold. The negative coefficient on the magnitude variable implies that increasing the size of the discount rate change leads to more than a proportionate increase in the ' $\mathrm{T}$-bill response, provided that the change is in the same direction as the previous one. Thus, perhaps markets interpret 100 basis-point changes in the discount rate as especially convincing signals of a changing environment. The negative coefficient on the unemployment rate indicates that relatively large responses in the T-bill rate are more likely when the unemployment rate is high. One interpretation is that the market believes that the Fed reacts to high unemployment with active policy steps to stimulate the economy, so the market tends to key off discount rate changes and Process 2 is likely to hold.

In fitting the change in the T-bill rate on the days the discount rate changes, the mixture model attains an $\mathrm{R}^{2}$ of .726 (on days when the discount rate does not change, the $\mathrm{R}^{2}$ is zero by construction). ${ }^{12}$ Estimation of the $T$-bill response, using the technical/non-technical classifications from Federal Reserve announcements, results in a lower $\mathrm{R}^{2}$ of $.459 .{ }^{13}$ Furthermore, as table 2 shows, the mixture model provides a superior fit across both the October 1979-October 1982 period, when the Fed targeted non-borrowed reserves, and the rest of the sample.
Table 2

\section{Sum of Squared Residuals} when $\triangle D R \neq 0$

\begin{tabular}{|c|c|c|}
\hline Sample period & Mxture model & $\begin{array}{l}\text { Technical } \\
\text { Non } \\
\text { technical }\end{array}$ \\
\hline Full sample & 1837 & 3076 \\
\hline $1979-1982$ & 1448 & 1936 \\
\hline Outside $1979-1982$ & 390 & $1 / 41$ \\
\hline
\end{tabular}

The generality of the mixture model, relative to the technical/non-technical dichotomy, is that the probability of Process 1 vs. Process 2 can lie anywhere between zero and one; table 3 shows that the probabilities of the high-response process lie between 10 and 90 percent for five responses. Table 3 also indicates that the differences between the mixture model and the technical/ non-technical regression derive mainly from the fact that 33 of the 56 discount changes are nontechnical, yet the estimated probabilities of Process 2 determining the T-bill responses in the mixture model sum only to 12.2 , which indicates that non-technical discount rate changes are considerably heterogeneous with respect to the market response. This concurs with Thornton (1991) who notes that the T.bill rate does not change significantly following some non-technical changes. Nevertheless, almost all high-response cases are non-technical, and on only three occasions did the probability of Process 2, the high-response case, exceed 0.9 outside of October 1979-October 1982, the period of non. borrowed reserves targeting. It is not yet clear; then, whether the large T-bill responses between 1979 and 1982 were due to the operating procedure or the abnormally high unemployment rates. The next section shows that both the

\footnotetext{
toSuch a version of the model was estimated with separate coefficients for the magnitude and the sign change. Not surprisingly, the coefficient on the sign-change variable suggests that changes in direction lead to small responses in the T-bill rate; with only eight occurrences, however, the standard error is large, making the point estimate unreliable. The coefficient on the magnitude of the discount fate change, which can use all 56 observations, is statis. tically significant. Overall, both the version reported in the paper and the one described here give nearly identical estimates of the response levels and the number of highresponse cases.
}

${ }^{11}$ Other variables tried but found not to be significant were the most recent change in the inflation rate and the growth rate of industrial production.

\footnotetext{
12Note that a mixture model with constant prior probabilities fits almost as well as the one with time-varying prior probabilities. Nevertheless, the prior probabilities do exhibit statisticaliy significant variation, and by estimating their co-movements with other variables, we gain some insight as to what lies behind the T-bill responses.

13This regression follows Thornton (1982) who first documented that dividing discount rate changes into "technica" and "nonntechnical" changes leads to a regression of interest rate changes on discount rate changes where non-technical changes are significant and technical changes are insignificant: $\Delta \mathrm{TB}_{\mathrm{t}}=\delta_{0}+\mathrm{A}(\mathrm{L}) \Delta \mathrm{TB}_{\mathrm{t}-1}+\delta_{\mathrm{t}} \mathrm{D}_{\mathrm{t}} \Delta \mathrm{DR}_{\mathrm{t}}+\delta_{2}\left(1-\mathrm{D}_{\mathrm{t}}\right)$ $\Delta D R_{t}+\varepsilon_{t}$, where $D_{t}$ is a dummy variable that equals one when the discount change is technical. The estimates of $\delta_{1}$ and $d_{2}$ are .036 and .540 , respectively, for this data set.
} 
Table 3

Specific Discount Rate Changes

\begin{tabular}{|c|c|c|c|c|}
\hline Date & $\begin{array}{l}\text { Change in } \\
\text { discount rate }\end{array}$ & $\begin{array}{l}\text { Change in } \\
\text { T-bill rate }\end{array}$ & $\begin{array}{l}\text { Probability of high- } \\
\text { response process }\end{array}$ & Non-technical $=1$ \\
\hline $1-15-73$ & 0.50 & 0.030 & $1.5028 \mathrm{E}-06$ & 0 \\
\hline $2-26.73$ & 0.50 & 0.210 & 0,043218 & 1 \\
\hline $4-23-73$ & 0.25 & 0.060 & 0.0099814 & 0 \\
\hline $5-11-73$ & 0.25 & 0.230 & 0.13455 & 0 \\
\hline $6.11-73$ & 0.50 & 0.080 & 0.00061177 & 1 \\
\hline $7-02-73$ & 0.50 & 0.380 & 0.91483 & 1 \\
\hline $8-14-73$ & 0.50 & 0.230 & 0.073415 & 0 \\
\hline $4-25-74$ & 0.50 & 0.190 & 0.023996 & 1 \\
\hline $2-09-74$ & -0.25 & -0.180 & 0.023127 & 1 \\
\hline $1-06-75$ & -0.50 & -0.060 & 0.0015696 & $\dagger$ \\
\hline $2-05-75$ & -0.50 & -0.150 & 0.029039 & 0 \\
\hline $3-10-75$ & -0.50 & 0,060 & $3.9024 \mathrm{E}-05$ & 1 \\
\hline $5-16-75$ & -0.25 & 0.010 & 0.021211 & 0 \\
\hline $1-19-76$ & -0.50 & -0.080 & 0.0027500 & 0 \\
\hline $11-22-76$ & -0.25 & -0.060 & 0.037609 & 0 \\
\hline $8-30-77$ & 0.50 & 0.020 & $2.8641 E-06$ & 0 \\
\hline $10-26-77$ & 0.25 & -0.050 & 0.0038216 & 0 \\
\hline $1.09-78$ & 0.50 & 0.390 & 0.96901 & 1 \\
\hline $5-1+-78$ & 0.50 & -0.070 & $7.5165 E-06$ & 0 \\
\hline $7-03-78$ & 0.25 & -0.060 & 0.0024606 & 0 \\
\hline $8-21-78$ & 0.50 & -0.040 & $1.9156 \mathrm{E}-05$ & 1 \\
\hline $9-22-78$ & 0.25 & 0.110 & 0.035044 & 1 \\
\hline $10-16-78$ & 0.50 & 0.060 & 0.00048244 & 1 \\
\hline $11-01-78$ & 1.00 & 0.100 & $1.3174 \mathrm{E}-10$ & 1 \\
\hline $7-20-79$ & 0.50 & 0.160 & 0.012015 & 1 \\
\hline $8-17-79$ & 0.50 & 0.060 & 0.00052925 & 1 \\
\hline $9-19-79$ & 0.50 & -0.200 & $1.0186 \mathrm{E}-07$ & 0 \\
\hline $10-09-79$ & 1.00 & 1.120 & 0.99437 & 1 \\
\hline $2-15-80$ & 1.00 & 0.570 & $0.750+2$ & 1 \\
\hline $5-29-80$ & -1.00 & 0.220 & $2.0124 \mathrm{E}-06$ & 0 \\
\hline $6-13-80$ & -1.00 & -0.020 & 0.076875 & 0 \\
\hline $7-28-80$ & -1.00 & 0.160 & 0.022486 & 0 \\
\hline $9-26-80$ & 1.00 & 0.460 & 0.00035858 & 1 \\
\hline $11-17-80$ & 1.00 & 0.800 & 0.96824 & 1 \\
\hline $12-05-80$ & 1.00 & 0.980 & 0.99060 & 1 \\
\hline $5-05-81$ & 1.00 & 0.600 & 0.86819 & 1 \\
\hline $11-02-81$ & -1.00 & -0.060 & $2.4887 \mathrm{E}-05$ & 0 \\
\hline $12-04-81$ & -1.00 & -0.580 & 0.90221 & 0 \\
\hline $7-20-82$ & -0.50 & -0.400 & 0.56798 & 1 \\
\hline $8-02-82$ & -0.50 & -0.810 & 0.86346 & 1 \\
\hline $8-16-82$ & -0.50 & -0.580 & 0.72376 & 1 \\
\hline $8-27-82$ & -0.50 & 0.700 & 0.019068 & 0 \\
\hline $10-12-82$ & -0.50 & -0.370 & 0.99147 & 0 \\
\hline $11-22-82$ & -0.50 & -0.140 & 0.070041 & 1 \\
\hline $12-14-82$ & -0.50 & -0.320 & 0.96461 & $i$ \\
\hline $4-09-84$ & 0.50 & -0.090 & $1.0819 \mathrm{E}-07$ & 0 \\
\hline $11-23-84$ & -0.50 & -0.100 & $4.8352 E-05$ & 1 \\
\hline $12-24-84$ & -0.50 & -0.130 & 0.010614 & $i$ \\
\hline $5-20-85$ & -0.50 & -0.140 & 0.014009 & $i$ \\
\hline $3-07-86$ & -0.50 & -0.080 & 0.0019898 & 1 \\
\hline $4-21-86$ & -0.50 & 0.000 & 0.00013878 & 0 \\
\hline $7 \times 11.86$ & -0.50 & -0.100 & 0,0034851 & 0 \\
\hline $8-21-86$ & -0.50 & -0.130 & 0.0088348 & 1 \\
\hline $9-04-87$ & 0.50 & 0.190 & 0.00044880 & $i$ \\
\hline $8-09-88$ & 0.50 & 0.220 & 0.076418 & $i$ \\
\hline $2-24-89$ & 0.50 & 0.040 & 0.00018991 & 1 \\
\hline
\end{tabular}


Table 4

Sum of Squared Forecast Errors

\begin{tabular}{|c|c|c|c|}
\hline $\begin{array}{l}\text { Sample } \\
\text { period }\end{array}$ & Forecast 1 & $\begin{array}{c}\text { Technical } / \\
\text { Non-technical }\end{array}$ & Forecast 2 \\
\hline Full sample & 3.552 & 3.076 & 2.404 \\
\hline $1979-1982$ & 2.721 & 1.936 & 1.711 \\
\hline Outside $1979-1982$ & .831 & 1.141 & .694 \\
\hline
\end{tabular}

operating procedure and the unemployment rate matter for forecasting.

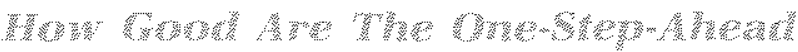

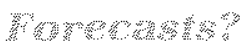

Substitution of the prior probabilities, Prob. $\left(S_{t}=1 \mid Z_{t}\right)$, into equation 1 for $S_{1}$ gives onestep-ahead forecasts for this model. Comparing the mixture model's sum of squared forecasts errors, found in table 4 under forecast 1 , with the sum of squared residuals from the technical/ non-technical regression provides a relative measure of forecast performance.

The mixture model's forecast 1 does not fare well from October 1979-October 1982, although it performs better than the technical/non-technical regression outside this period. One interpretation is that Federal Reserve announcements of discount rate changes, on which the technical/ non-technical classifications are based, take on special importance during periods when the Fed is targeting non-borrowed reserves. To learn about this, we add a dummy variable, which equals one when there is a non-technical change during the 1979-82 period, into $Z_{1}$ in the prior probabilities of equation 2 of the mixture model. ${ }^{14}$ The sum of squared forecast errors is reported in table 4 under forecast 2 . Knowing whether the discount change is technical greatly improves the forecasts between 1979.82. One possible explanation is that market watchers can directly observe discrete shifts in Fed policy by watching the federal funds rate when it is the operating target. Under non-borrowed reserves targeting, however, the funds rate is market-determined,

14Adding a second dummy variable for non-technical changes outside 1979-82 does not improve the estimates significantly.

15 It is easy to formulate in-sample forecasts that suggest, for example, that people in 1932 should have known that it so discrete shifts in Fed policy are more likely to be revealed through the discount rate, thereby enhancing the informational value of discount rate changes, as it takes time for shifts in policy to translate into sustained changes in the rate of reserves growth.

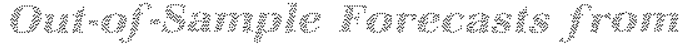 wents}

Compared with in-sample forecasting, out-ofsample forecasting offers a stiffer and more economically meaningful test of an empirical model. Thus, it is useful to compare forecasts from the mixture model and the technical/nontechnical regression for the seven discount rate changes beginning in December 1990, using the coefficients estimated over the $1972-89$ period. ${ }^{55}$ Table 5 summarizes the results.

The time-varying prior probabilities of Process 1 vs. Process 2 are clearly illustrated in table 5 . As the unemployment rate increases, the prior probability of Process 2 increases, perhaps as markets expect active policy steps from the Fed to combat recession. Also, the change in December 1991 leads to a much higher prior probability of the high-response process, because it was a change of 100 basis points and the sign of the discount rate change did not change from the previous one. The technical/non-technical regression, in contrast, consistently overpredicts the $T$-bill responses with its characterization that all non-technical discount rate changes of the same size should have the same effect on the $\mathrm{T}$-bill rate.

was a great time to buy stocks. When making reat-world decisions, however, people have to forecast into the very uncertain future, a fact captured in out-of-sample forecasting. 


\section{Table 5}

\section{Out-of-Sample Forecasting}

Date:

12-19-90 2-04-91 4-30-91 9-13-91 11-6-91 12-20-91 7-02-92

Unemployment rate

Technical change

Pror Probability Process 1

Change in Discount Rate

Change in T-bill Rate

Technical forecasted $\mathrm{ATB}$

Mixture torecasted ATB

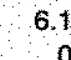

.999

$-50$

$-.11$

$-273$

$-.027$
6.5

6.5
0

875

$-.50$

$-.02$

$-.273$

$-.064$

\section{6}

6.6
0

869 .

$-.50$

$-.08$

$-273$

$-.066$

6.8
0
859

$-.50$

$-.06$

$-.273$

$-069$

$\begin{array}{rrr}6.9 & 7.1 & 7.8 \\ 0 & 0 & 0 \\ 853 & 372 & 205 \\ -.50 & -1.0 & -.50 \\ -13 & -.30 & -.31 \\ .273 & -.546 & -.273 \\ .070 & -.475 & -.274\end{array}$

Overall, the mixture model with time-varying prior probabilities fits the changes in the T-bill rate better than the technical/non-technical regression; it also provides better one-step-ahead forecasts, given that the prior probabilities use information about whether the change is technical or non-technical during periods when the operating target is non-borrowed reserves. Furthermore, the variables determining the prior probabilities of the two response levels may reveal something about the market's beliefs about discount rate policy.

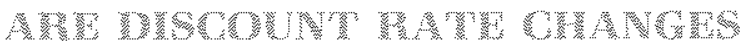 A}

Previous research has considered that whether a discount rate change is anticipated or not is a potentially important factor in determining how strongly the Tubill rate responds. ${ }^{16}$ In other words, when market rates do not respond to a non-technical change in the discount rate, it might be due to the fact that the market anticipated the change and market rates had already moved before the discount change. The relevance of this scenario hinges on whether market participants can predict with reasonable accuracy both the timing and magnitude of discount rate changes. The analysis here will follow the work of Hakkio and Pearce (1992) by lumping together

16Examples are Thornton (1986, 1991), Roley and Troll (1984), Smirlock and Yawitz (1985), and Hakkio and Pearce (1992).

tThis restriction is simply due to a lack of a sufficient number of 25,50, and 100 basis-point increases and decreases to allow for full separation of discount changes based on their sizes. Smirlock and Yawitz (1985), on the other hand, obtain an estimate of the expected change in the discount rate, not only the prior probability of a change. This comes at a cost, however, because their model does not consider the discrete nature of discount rate changes, t.e., their different-sized changes in the discount rate and concentrating on whether the direction and timing of changes are predictable ${ }^{17}$ The distinction will be that Hakkio and Pearce either estimate sub-samples of discount rate increases and decreases separately, or estimate a multinomial logit model, neither of which recognizes the ordering inherent in discount rate changes (decrease, no change, increase). The ordered probit model employed here takes into account that the probability of a decrease in the dis. count rate, relative to the probability of no change, does not remain constant as the probability of an increase changes; the multinomial logit requires this assumption. ${ }^{18}$

Maddala (1983) presents the basic ordered probit model, written here in terms of discount rate changes:

(3) Prob.(decrease $\left.\mid X_{t-1}\right)=F\left(X_{t-1}^{\prime} \beta\right)$

$$
\begin{aligned}
& \text { Prob.(no change } \left.\mid \mathrm{X}_{\mathrm{t}-1}\right)=\mathrm{F}\left(\mathrm{X}_{\mathrm{t}-1} \beta+\mathrm{c}\right)-\mathrm{F}\left(\mathrm{X}_{\mathrm{t}-1} \beta\right) \\
& \text { Prob.(increase } \left.\mid \mathrm{X}_{\mathrm{t}-1}\right)=1-\mathrm{F}\left(\mathrm{X}_{\mathrm{t}-1} \beta+\mathrm{c}\right)
\end{aligned}
$$

where $X_{t-1}$ is a vector of information available at time $\mathrm{t}-1, \mathrm{~F}(\cdot)$ is the cumulative normal density function and $\mathrm{c}$ is a positive constant.

Furthermore, rather than view the anticipated/ unanticipated dichotomy as an alternative to

model ignores the fact that the Fed always changes the discount rate by a minimum of 25 basis points, which effectively makes the likelihood of a discount tate change trivialyy small in many time periods.

${ }^{18} \mathrm{Applications}$ of the multinomial logit model are often criticized for assuming an "independence of irrelevant aiternatives" when this property fails to hold for the choices being modeled. See Maddala (1983) for some examples. 
Table 6

Response Coefficients for T-Bill

\begin{tabular}{|c|c|c|c|c|}
\hline & $\begin{array}{l}\text { Technical } \\
\text { Increase }\end{array}$ & $\begin{array}{l}\text { Technical } \\
\text { Decrease }\end{array}$ & $\begin{array}{c}\text { Non-technical } \\
\text { Increase }\end{array}$ & $\begin{array}{c}\text { Non-technical } \\
\text { Decrease }\end{array}$ \\
\hline Anticipated & $\alpha_{1}$ & $\alpha_{2}$ & $\alpha_{3}$ & $\alpha_{4}$ \\
\hline Unanticlpated & $a_{5}$ & $-a_{5}$ & $a_{6}$ & $-a_{6}$ \\
\hline
\end{tabular}

technical/non-technical as Smirlock and Yawitz (1985) do $_{\text {; }}$ we can estimate the market's responses to polychotomous discount rate changes: anticipated technical increases in the discount rate; anticipated non-technical decreases; unanticipated technical changes; etc. In all there are eight different responses, as outlined in table 6 .

Hence, the hypothesis that anticipations of discount rate changes do not significantly move the T-Bill rate cannot be rejected if $\alpha_{1}=\alpha_{2}=\alpha_{3}=\alpha_{4}$ $=0$ cannot be rejected. The model imposes symmetrical responses for unanticipated increases and decreases in the discount rate simply due to sample-size constraints. With only 23 and 33 technical and non-technical changes, respectively, it is not possible to obtain good estimates of separate coefficients for either unanticipated technical increases and decreases or unanticipated non-technical increases and decreases.

The sequential nature of the model means that we first use time $t-1$ information to estimate the respective probabilities of a decrease, no change or an increase in the discount rate at time $t$. Then, given the direction of the discount rate change, we use time $t-1$ information to estimate the probabilities of technical and nontechnical changes in the discount rate. Together these prior probabilities give the prior probability of a technical discount rate increase:

(4) Probability (tech.increase $\left.\mid \mathrm{x}_{,-1}\right)$

$=$ Prob.(increase $\left.\mid \mathrm{x}_{\mathrm{t}-\mathrm{t}}\right)$

$\times$ Prob.(tech.changelincrease, $\mathrm{x}_{1-1}$ )
The objective here is to regress changes in the T-bill rate on the prior probabilities of discount rate changes, such as the one in equation 4 , to see whether market interest rates react to changing anticipations of discount rate changes. ${ }^{19}$

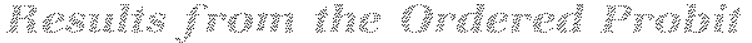

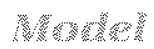

Estimates from this model help determine which explanatory variables are useful in predicting discount rate changes and to what extent discount rate changes are predictable. ${ }^{2 \theta}$ The results from estimating equation 3 with weekly data (Friday-to-Friday) are in table 7 and

Table 7

Ordered Probit Coefficients

\begin{tabular}{|c|c|c|}
\hline Variable & Coefficient & tstatistic \\
\hline htercept & 389 & 8.94 \\
\hline Spread & -217 & 4.09 \\
\hline Industral Producton: & -2794 & 388 \\
\hline Unemployment Rate & 265 & 5.00 \\
\hline Constant (c) & 434 & 2411 \\
\hline
\end{tabular}

indicate that discount rate changes are somewhat predictable in a qualitative sense; figures 1 and 2 show that the prior probability of a discount rate decrease or increase often peaks near the actual changes, but it never reaches one-half. Significant explanatory variables for the discount rate changes are the spread between the repurchase rate and the discount rate,

\footnotetext{
19We say "anticipations of discount rate changes" and not "anticipated discount rate changes," because the model should include the effect on the T-bill rate of cases in which a discount change seemed likely, but none occurred The estimates of Smitock and Yawitz (1985) and Thomton (1991) do not fully account for unfulfilled anticipations of discount rate changes.
} 20The variables fried had been suggested in Hakkio and
Pearce (1992). 


\section{Figure 1 \\ Prior Probability of a Discount Rate Decrease}

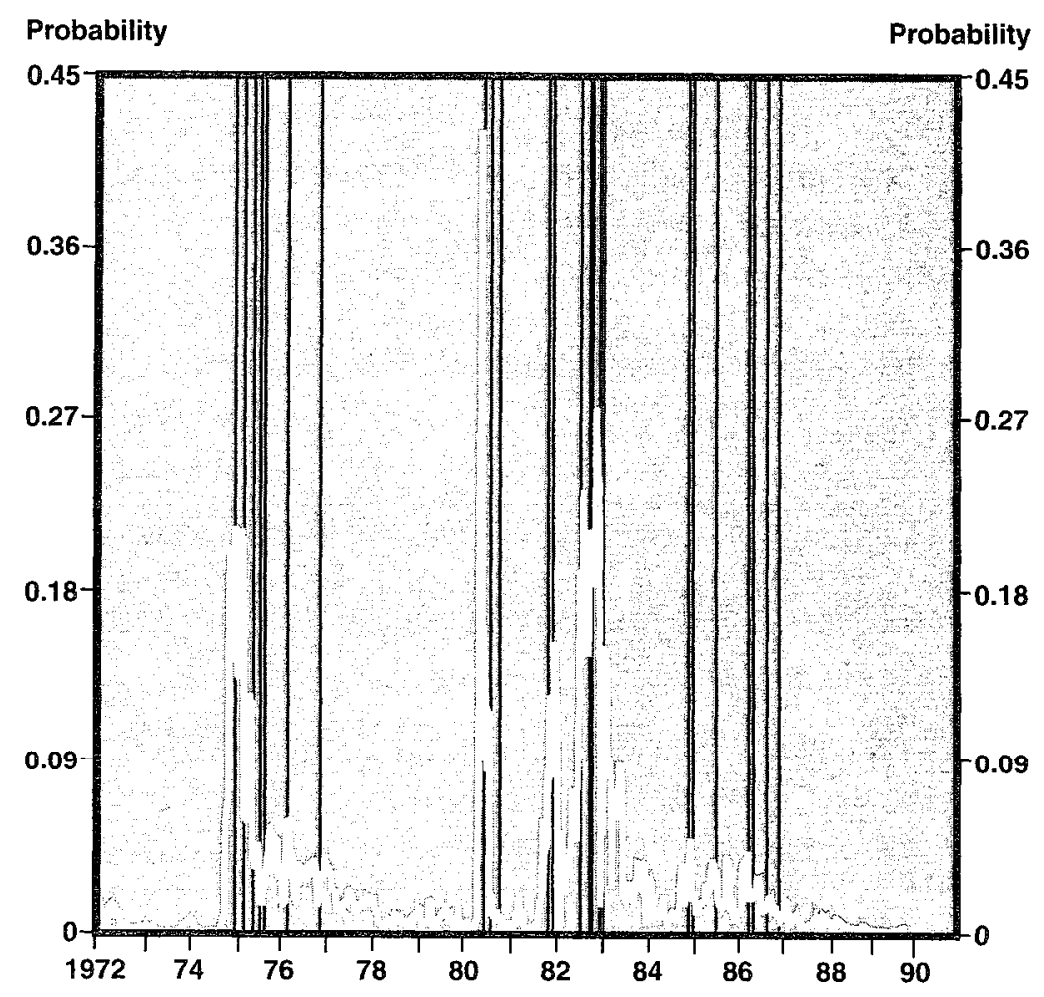

NOTE: Vertical lines represent dates of discount rate cuts.

industrial production and the unemployment rate; money growth is not significant.

The signs of the ordered probit coefficients imply that, as the repurchase rate rises above the discount rate, the probability of a discount rate hike increases; low industrial production and high unemployment raise the probability of discount rate cuts, so all coefficients have the expected signs. The growth rate of industrial production is not significant in determining the prior probabilities in the mixture model, but is significant in predicting discount rate changes, which means that industrial production helps indicate when discount rate changes will take place, but not how market rates will respond. The unemployment rate, on the other hand, is significant in both contexts. Figure 3 provides some interpretation by showing that early in recessions sometimes monetary policy easings bring discount rate decreases, yet other times the discount rate simply follows the cyclical path of market rates. Late in recessions, however, when the unemployment rate reaches its cyclical peak, monetary policy easings usually take the discount rate substantially below its pre-recession level.

Correlations between the probabilities of the high-response process and the unemployment rate and the growth rate of industrial production also support the idea that the market believes that the Fed shifts monetary policy more often in response to unemployment than output. The correlation coefficient between the probability of the high-response process and the unemployment rate is .31 ; it is only .09 between the high- 


\section{Figure 2 \\ Prior Probability of a Discount Rate Increase}

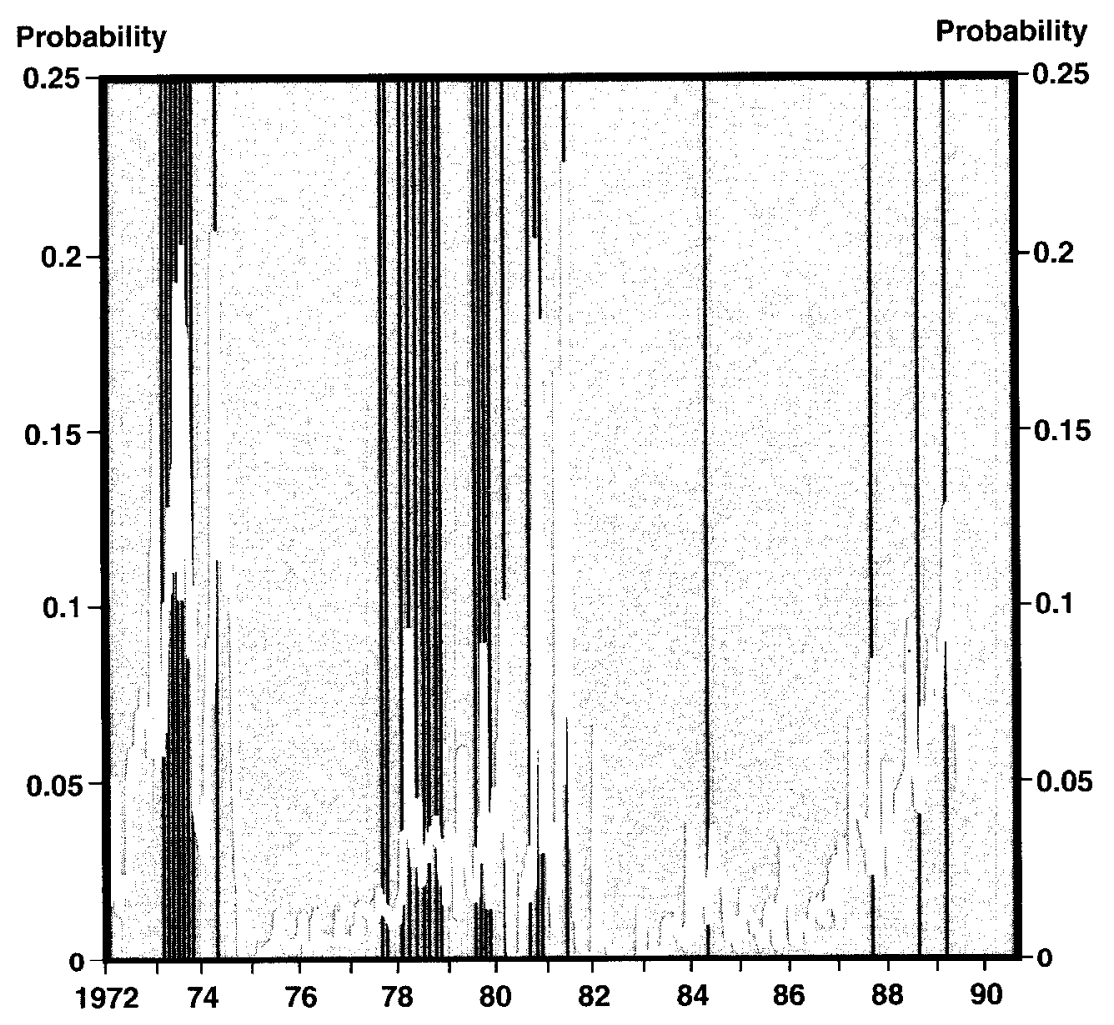

NOTE: Vertical lines represent dates of discount rate increases.

response probability and the growth rate of industrial production.

The ordered probit gives the first probability on the right-hand side of equation 4 . The second. the Prob.(technical change|increase, $\mathrm{X}_{\mathrm{t}-1}$ ), comes from modeling the technical/non-technical binary variable with an ordinary probit, using all the discount rate increases in the sample. ${ }^{21}$ The estimated probit coefficients and $X_{t-1}$ can then be used to calculate Prob.(technical change|increase, $\mathrm{X}_{\mathrm{t}-1}$ ) for each observation. When using the Federal Reserve announcements to form the binary dependent variable (technical/non-technical), however, none of the explanatory variables is a statistically significant predictor of whether discount rate increases are likely to be technical or non-technical. Results fur buth prubil mudels, one each for increases and decreases, appear in table 8 .

The probability of the discount change being technical is $F\left(X_{1-1}^{\prime} \beta\right)$, where $F(\cdot)$ is the cumulative

21The ordinary probit model is similar to the ordered probit of equation 3, except that the dependent variable is binomial, rather than trinomial. 


\section{Figure 3 \\ The Discount Rate and the Unemployment Rate}

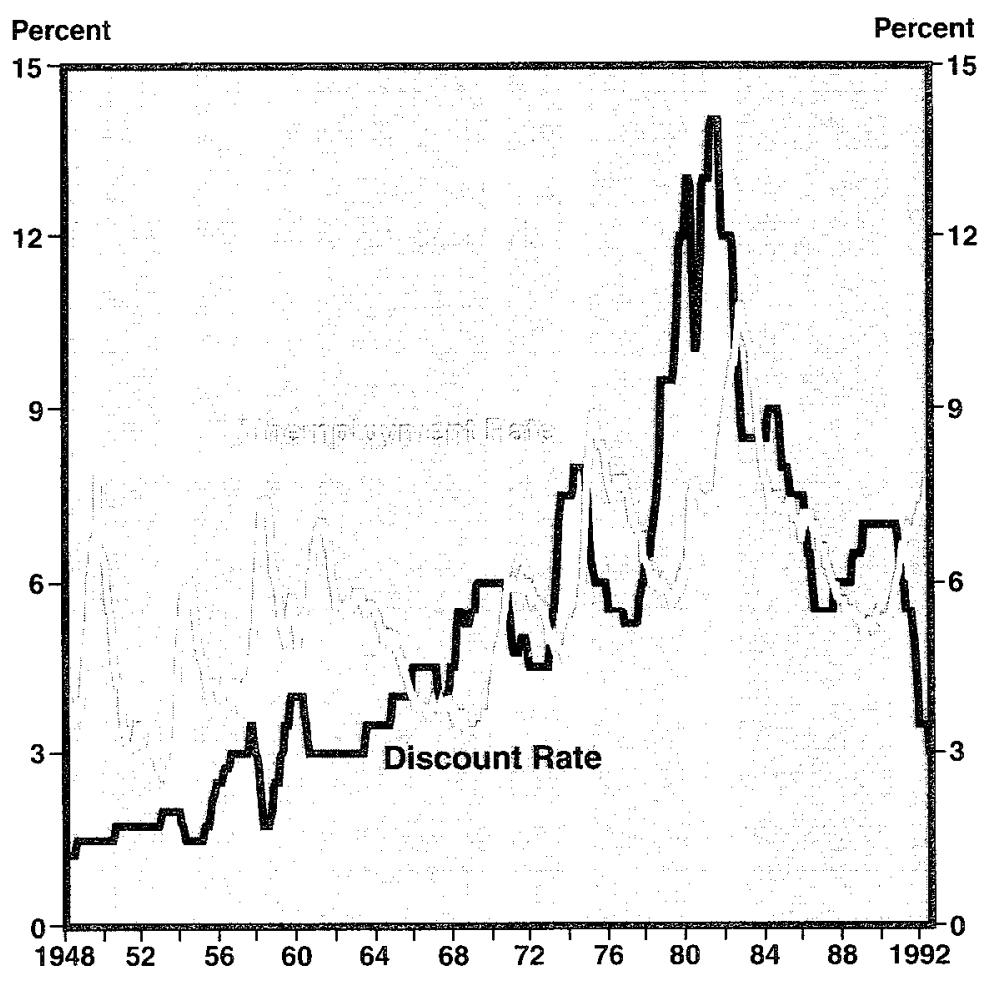

NUIE: LIght snaded areas represent perlods of business recession.

density function for the normal distribution, so that a positive coefficient on a variable means that the probability that a change is technical increases with that variable. Despite the lack of statistical significance for all coefficients except that on the spread between the federal funds rate and the discomint rate for the decreases, we nevertheless use fitted values generated with these coefficients in testing whether anticipations of discount rate changes affect T-bill rates. This is because the limiting factor with respect to anticipating the timing and nature of discount rate changes is most likely an inability to predict the timing, given that in the ordered probil the prior probabilities of discount rate decreases and increases never reach 50 percent and 25 percent, respectively, as shown in figures 1 and 2 .

\section{T-Bill Responses to Anticipated Discount Rate Changes}

The results of estimating table 6's response coefficients appear in table 9. None of the four anticipated variables has a significant coefficient, although the F-test of joint significance gives an $\mathrm{F}_{4,905}$ statistic of 3.115 , which lies between the critical value $F_{4, \infty}=3.32$ at the 99 percent confidence level and the 95 percent critical value of $2.37 .^{22}$ Thus when using the 
Table 8

Probability of Technical vs. Non-technical

\begin{tabular}{|c|c|c|c|c|}
\hline \multirow[b]{2}{*}{ Variable $\left(x_{t-1}\right)$} & \multicolumn{2}{|c|}{ Discount Rate Increases } & \multicolumn{2}{|c|}{ Discount Rate Decreases } \\
\hline & Coefficient & t-statistic & Coefficient & t-statistic \\
\hline Intercept & -.626 & .323 & 1.71 & .794 \\
\hline Spread & .119 & .412 & -1.29 & 2.273 \\
\hline Mi Growth Pate: & 8.48 & 1.32 & 2.61 & .494 \\
\hline Industrial Production Growth & -38.24 & .654 & 30.73 & .823 \\
\hline Unemployment Rate & -.079 & .251 & -.272 & 1.01 \\
\hline
\end{tabular}

technical/nontechnical classifications, it might appear that anticipations of discount rate changes have an effect on the $\mathrm{T}$-bill rate. It is unclear, however, whether this result holds when we use the mixture model's classifications. Consequently, we repeat the exercise using a binary variable generated from the posterior probabilities from the mixture model, whereby a discount rate change is classified as coming from Process 2 if the Prob.(Process $2 \mid \Delta T B) \geq 0.5$. Only the dependent binary variable (Process 1/Process 2) changes from the previous analysis; the probabilities of discount rate changes from the ordered probit still apply. Table 10 contains new estimates of the $T$-bill response coefficients.

With the mixture model classifications, the timing of discount rate changes does not appear to be sufficiently predictable to uncover evidence that anticipations of discount changes lead to movements in the $\mathrm{T}$-bill rate. In table 10, no coefficient on an anticipated variable is significant, and the $F_{4,04}$ statistic for joint significance is only 1.77 , which is less than the 95 percent critical value of 2.37 . We conclude that the timing of a discount rate change is difficult to predict, even at the weekly horizon, and anticipations of discount rate changes do not appear to be major determinants of movements in the T-bill rate, especially when classifying the discount rate changes as high- or low-response changes.

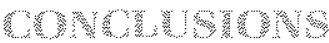

This paper presents a mixture model of two levels of T-bill responses to discount rate changes. All of the model's results are compared with results obtained from classifying discount rate changes as technical or nonutechnical, which is the standard approach in the literature.

The mixture model yields superior results with the single exception of forecasting $T$-bill responses during the $1979-82$ period of nonborrowed reserves targeting. Conditioning the mixture model's forecasts on whether the discount change is technical or non-technical from 1979-82 remedies this shortcoming. Moreover the mixture model is well-suited to forecasting because it derives prior probabilities for each response level, which policymakers and market participants can use to analyze the likely impact of a discount rate change on market interest rates.

Table 9

\section{T-Bill Response Coefficients}

\begin{tabular}{|c|c|c|}
\hline Variable & Coefficient & t-statistic \\
\hline Intercept: & .030 & 1.50 \\
\hline Spread & -.049 & 2.45 \\
\hline Unanticipated Non-technical & .827 & 5.95 \\
\hline Unanticipated Technical & .230 & 1.10 \\
\hline Anticipated Non-technical Decrease & -.201 & 234 \\
\hline Anticipated Technical Decrease & -692 & 1.624 \\
\hline Anticipated Non-technical Increase & 3.123 & 1.639 \\
\hline Anticipated Technical Increase & -616 & .834 \\
\hline
\end{tabular}

Estimates of the market's responses to discount rate changes are consistent with the idea that the market believes in several stylized facts. First, discount rate changes of larger absolute magnitudes appear to generate proportionately larger responses in the T-bill rate. Second, markets look for the Fed to respond actively when the 
Table 10

\section{Alternative T-Bill Response Coefficients}

\begin{tabular}{|c|c|c|}
\hline Variable & Coefficient & -statistic \\
\hline Intercept: & -037 & 1,85 \\
\hline Spread & -047 & 247 \\
\hline Unanticipated Process 2 & 826 & 6.03 \\
\hline Unanticipated Process 1 & 174 & 833 \\
\hline Anticipated Process 2 Decrease & -785 & 1230 \\
\hline Anticipated Process 1 Decrease & -217 & 547 \\
\hline Anticlpated Process 2 Increase & 516 & 831 \\
\hline Anticlpated Process I Inctease & -273 & 168 \\
\hline
\end{tabular}

unemployment rate is high. Third, discount rate policy apparently becomes an important source of information transmission during periods of non-borrowed reserves targeting. This is probably because discrete shifts in Fed policy are not revealed through the federal funds rate under non-borrowed reserves targeting, thereby boosting the status of Federal Reserve announcements of discount rate changes as indicators of shifts in monetary policy. The technical/nontechnical dichotomy is much less able to separate these individual influences behind the market response to discount rate changes. Furthermore, the mixture model provides an econometric framework within which such stylized facts can be quantified to further our understanding of when and why some discount rate changes will have a significant impact on market interest rates.

The second half of the paper uses a sequential ordered probit model, an econometric model that is arguably more suited to estimating the extent to which discount rate changes can be anticipated than ones used previously in the literature. The estimates are consistent with Smirlock and Yawitz (1985) in that anticipations of discount rate changes might appear to affect the T-bill rate when the changes are classified as technical or non-technical. The evidence, however, does not support such a role for antic- ipations of discount rate changes when we use the mixture model to classify the discount rate changes.

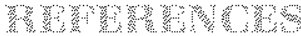

Batten, Dallas S., and Daniel L. Thornton. "Discount Rate Changes and the Foreign Exchange Market," Journal of International Money and Finance (December 1984), pp. 279-92.

Cook, Timothy, and Thomas Hahn. "The Information Content of Discount Rate Announcements and Their Effect on Market Interest Rates," Journal of Money, Credit and Banking (May 1988), pp. 167-80.

Dempster, A. P., N. M. Laird, and D. B. Rubin. "Maximum Likelihood from Incomplete Data via the EM Algorithm," Journal of the Royal Statistical Society (Ser. B Vol. 39 , No. 1, 1977), pp. $1-38$

Hakkio, Craig, and Douglas Pearce. "Discount Rate Policy Under Alternative Operating Regimes: An Empirical Investigation." International Review of Economics and Finance (Vol. 1, No. 1, 1992), pp. 55-72.

Hamilton, James D. "A New Approach to the Economic Analysis of Nonstationary Time Series and the Business Cycle," Econometrica (March 1990), pp. 357-84.

Maddala, G. S. Limited-Dependent and Qualitative Variables in Econometrics (Cambridge University Press, 1983).

Pagan, Adrian. "Econometric Issues in the Analysis of Regressions with Generated Regressors," International Economic Review (February 1984), pp. 221-47.

Quandt, Aichard E., and James B. Ramsey. "Estimating Mixtures of Normal Distributions and Switching Regressions" with Comment, Joumal of the American Statistical Association (December 1978), pp. 730-41.

Roley, V. Vance, and Rick Troll. "The Impact of Discount Rate Changes on Market Interest Rates," Federal Reserve Bank of Kansas City Economic Review (January 1984), pp. 27-39.

Smirlock, Michae J, and Jess B. Yawitz. "Asset Returns, Discount Rate Changes, and Market Efficiency," Journal of Finance (September 1985), pp. 1141-58.

Thornton, Daniel L. "Discount Rates and Market Interest Rates: What's the Connection?" this Review (June/July 1982), pp. $3-14$

"The Discount Rate and Market Interest Rates: Theory and Evidence," this Review (August/September 1986), pp. 5-21.

"The Borrowed Reserves Operating Procedure: Theory and Evidence," this Feview (Uanuary/February 1988), pp. 30-54

"The Market's Reaction to Discount Rate Changes What's Behind the Announcement Effect?' unpublished manuscript, Federal Reserve Bank of St. Louis (September 1991). 


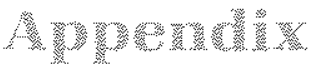

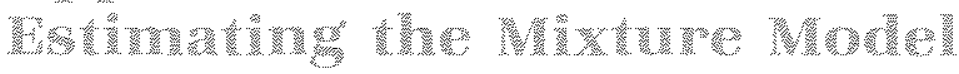

An intuitive method of estimating mixture models with unknown sample separation across the different processes is the ExpectationMaximization (EM) algorithm of Dempster, Laird and Rubin (1977). Following the EM algorithm, we write the joint density of the change in the T-bill rate and the unobserved state, $S_{t}$, conditional on $\mathrm{Z}_{\mathrm{f}}$ as

$$
\begin{aligned}
& \text { (A1) } \mathrm{f}\left(\Delta \mathrm{TB}, \mathrm{S}_{\mathrm{t}}=\mathrm{j} \mid \mathrm{Z}_{\mathrm{t}}\right)= \\
& \phi\left(\Delta \mathrm{TB}_{\mathrm{t}} \mid \mathrm{S}_{\mathrm{t}}=\mathrm{j}\right) \operatorname{Prob} .\left(\mathrm{S}_{\mathrm{t}}=\mathrm{j} \mid \mathrm{Z}_{\mathrm{t}}\right), \quad \mathrm{j}=0,1 \text {. }
\end{aligned}
$$

Taking logs and differentiating with respect to $\gamma=(\beta, \theta, \sigma)$ in $A 1$, we obtain scores of the loglikelihood under the assumption that the changes in the T-bill rate are normally distributed, so that when $\phi$ denotes the normal density function, the probability-weighted scores to be set to zero are

$$
\begin{aligned}
& \sum_{t=1}^{\mathrm{T}}\left[\text { Prob. }\left(\mathrm{S}_{\mathrm{t}}=0 \mid \Delta \mathrm{TB}_{\mathrm{t}}\right) \frac{\partial \ln \mathrm{f}\left(\Delta \mathrm{TB}_{\mathrm{t}}, \mathrm{S}_{\mathrm{t}}=0 \mid \mathrm{Z}_{\mathrm{t}}\right)}{\partial \gamma}\right. \\
& \left.+ \text { Prob. }\left(\mathrm{S}_{\mathrm{t}}=1 \mid \Delta \mathrm{TB}_{\mathrm{t}}\right) \frac{\partial \ln \mathrm{f}\left(\Delta \mathrm{TB}_{\mathrm{t}}, \mathrm{S}_{\mathrm{t}}=1 \mid \mathrm{Z}_{\mathrm{t}}\right)}{\partial \gamma}\right]
\end{aligned}
$$

The variance $\sigma_{1}$ is assumed to take on either of two values:

$$
\begin{aligned}
\sigma_{t} & =\sigma_{1} \text { if } t \in \text { (Oct 1979-Oct. 1982) } \\
& =o_{0} \text { otherwise. }
\end{aligned}
$$

Hence, the model allows for $\sigma_{z} \geq \sigma_{0}$, reflecting the greater volatility of interest rates experienced under the Fed's non -borrowed reserves operating procedure from October 1979 until October 1982. In the case where changes in the
T-bill rate are not normally distributed, the estimates are still consistent, but not as efficient as they would be if the true density were known and maximized. Furthermore, Hamilton (1990) has shown that disturbances to real GNP growth appear more homoscedastic and normal when modelled with a non-linear, state-switching model than with a linear model.

Finally , Bayes' Law allows for calculation of Prob. $\left(\mathrm{S}_{\mathrm{t}}=0 \mid \Delta \mathrm{TB}_{\mathrm{i}}\right)$ :

(A3) Prob. $\left(\mathrm{S}_{\mathrm{t}}=0 \mid \Delta \mathrm{TB}_{\mathrm{t}}\right)=$

$$
\begin{aligned}
& \text { Prob. }\left(\mathrm{S}_{\mathrm{t}}=0 \mid \mathrm{Z}_{\mathrm{t}}\right) \phi\left(\Delta \mathrm{TB}_{\mathrm{t}} \mathrm{S}_{\mathrm{t}}=0\right) / \\
& {\left[\text { Prob. }\left(\mathrm{S}_{\mathrm{t}}=0 \mid \mathrm{Z}\right)_{\mathrm{t}}\right) \phi\left(\Delta \mathrm{TB}_{\mathrm{t}} \mid \mathrm{S}_{\mathrm{t}}=0\right)} \\
& \text { +Prob. } \left.\left(\mathrm{S}_{\mathrm{t}}=1 \mid \mathrm{Z}_{\mathrm{t}}\right) \phi\left(\Delta \mathrm{TB}_{\mathrm{t}} \mid \mathrm{S}_{\mathrm{t}}=1\right)\right]
\end{aligned}
$$

The EM algorithm calls for the following steps to be taken in the estimation of $\left(\beta_{f} \theta, \sigma\right)$ :

Step 1

Given starting values of the parameters, calculate Prob. $\left(\mathrm{S}_{\mathrm{t}}=0 \mid \Delta \mathrm{TB}_{\mathrm{t}}\right)$ using Bayes' Law.

\section{Step 2}

Find $(\beta, \theta, \sigma)$ which sets the probabilityweighted scores equal to zero.

Step 3

With new estimates of $(\beta, \theta, \sigma)$, update the estimates of Prob. $\left(S_{1}=0 \mid \Delta T B_{t}\right)$.

Step 4

Iterate over 2 and 3 until convergence. 